\title{
Britain's superconductor teams compare notes and budgets
}

London

THE first major meeting of British scientists working on high-temperature superconducting ceramics, held at the Rutherford Appleton Laboratory last week, was for several delegates a disappointment that failed to address important issues. The meeting, arranged by the Science and Engineering Research Council (SERC), aimed to identify "the strategy that should be followed by the UK for the new high-temperature superconductors". And it was well attended originally, about 75 researchers closely involved in the field were invited, but the numbers eventually swelled to nearer 120. Many of those, though, had "muscled in", according to one prominent researcher, and in his view this resulted in time-wasting and detracted from the real business of the day.

The organizers hope that the meeting will result in greater collaboration between various groups, to avoid duplication and make best use of scarce funds. tivity has now largely ceased, and the British groups are concentrating their efforts on the fundamental physics of the new ceramics. But chronic shortage of funds remains the major obstacle to Britain's chances of competing realistically with foreign countries, particularly the United States and Japan. "There is despondency," said one delegate. "Britain is behind - in the last three or four months we have just not had the resources."

At the last count, 12 groups had applied to SERC for grants in the next round totalling $£ 1.4$ million, out of SERC's physics committee's total budget for the round of $£ 1.5$ million. The committee's chairman, Professor Lawrie Challis, concedes that the situation is "very worrying".

In the short term there seems little hope of cash from other sources. Industrialists Talk of room-temperature superconduc-

were present at last week's meeting, but it was felt that the potential importance of the present work was not impressed upon them sufficiently strongly. The Department of Trade and Industry (DTI) sent a representative with a statement to assure delegates that DTI was aware of the im portance of the field. However, he had no hard proposals for funding, and few dele-

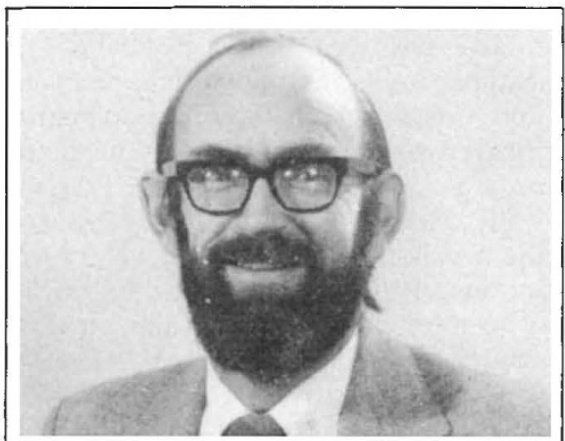

The SERC Rutherford Appleton Laboratory, the venue for last week's British superconductor gathering, now has a new director, Dr Paul Williams. Dr Williams, aged 53, has been associated with the laboratory since 1960. The Rutherford Appleton's approach to the fundamental physics of superconductor ceramics is exemplified by the letter on page 45 of this issue.

gates held out much hope for the rapid cash support that is needed. A DTI spokesman in London said that the matter was being considered "at the highest level". The most likely source of DTI funding would come from its recently announced LINK initiative, which aims to encourage collaboration between universities and industry. But while research efforts are being concentrated on fundamental aspects, DTI's involvement remains doubtful in the near future.

Despite the misgivings, most delegates welcomed the opportunity to meet fellow workers. Greater collaboration might yet result, but the shortage of funds is stifling progress.

Simon Hadlington

\section{Spending to keep up with the Japanese}

\section{Washington}

In tune with the popular theme of industrial competitiveness, the US National Science Foundation (NSF) has announced that special funds will be available for research into the new superconductors. The overt hope is that a solid foundation of research will enable US industries to gear up quickly for the anticipated commercial applications.

Three materials research laboratories, at Northwestern and Stanford Universities and at the University of Illinois at Urbana-
Champaign, will benefit from an immediate award of \$1 million. Another $\$ 60,000$ will be distributed as 'quick start' grants to researchers with promising techniques for turning the ceramic superconductors into usable forms and devices.

NSF director Erich Bloch admits the programme is an attempt to keep up with Japan, but says "American industry has also acted aggressively". He extols research into superconductivity as an example of the new-found cooperative spirit between universities and industry.

\section{Transitions are hotting up}

\section{London}

Media coverage of "Soviet Science Day", celebrated each year in April, focused this year on the topical phenomenon of hightemperature superconductivity. According to Pravda, there are two teams working in this field in the Soviet Academy of Sciences, one at the Institute of Crystallography and one at the Lebedev Physics Institute. The latter team, headed by $\mathrm{Dr}$ Aleksandr Golovashkin, is working on yttrium ceramics and early in April reported superconductivity transitions commencing at $250 \mathrm{~K}$ in freshly-prepared specimens. With the passage of time, however, Golovashkin told Pravda, the transitions disappear.

According to the government news agency TASS, the team have also observed the Josephson effect in an yttrium ceramic at around $73 \mathrm{~K}$, a result which, notes TASS, could be important for future computer technology.

Such announcements in the general media, in advance of scientific publication (due shortly in JETP Letters), are unusual. This departure is pre-sumably due partly to the current policy of Glasnost but also to a desire to be seen at the forefront of a field which is attracting such attention in the West. Golovashkin may have been over-modest in his interview however; according to unofficial reports at a recent meeting in Pisa, the Soviet transition is completed at $176 \mathrm{~K}$, considerably higher than any other reported to date. Vera Rich - David Lindley adds from Washington: Rumours of resistivity changes at $200 \mathrm{~K}$ or higher have circulated around US laboratories since the new ceramic superconductors were first discovered, but the measurements have been hard to reproduce, and full evidence for superconductivity has been lacking. J.T. Chen and colleagues, at Wayne State University in Detroit, claimed some weeks ago to have measured unambiguously the a.c. Josephson effect in ceramic samples, but the experiment is difficult and the signal can be mimicked by less exotic effects, such as formation of diodes at grain boundaries.

The Wayne State group sees a transition beginning at $240 \mathrm{~K}$ and completed by $200 \mathrm{~K}$, and their result seems to be holding up. Presumably, grains of a different crystal structure superconduct at a higher temperature, but the whole sample does not become superconducting until cooled to $100 \mathrm{~K}$ because the grains are too sparsely distributed to allow a connected current path. Certainly, no one has yet come up with a bulk sample that is superconducting at $240 \mathrm{~K}$ and, as in the Soviet report, the high-temperature phase often disappears as ceramic samples age. 